\title{
Assurance System for the Teaching Quality of Undergraduate Students in Clinical Medicine
}

\author{
Shengguang Yan ${ }^{1, a}$, Jaebok Seo ${ }^{2, b}$, Hefei $\mathrm{Li}^{1, \mathrm{c}}$, Lijuan $\mathrm{He}^{3, \mathrm{~d}}$ \\ ${ }^{1}$ North China University of Science and Technology, Tangshan City, Hebei Province, China, \\ 063000 \\ ${ }^{2}$ Jeonju University, Jeonju-si, Jeollabuk-do, South Korea, 55069 \\ ${ }^{3}$ Kailuan General Hospital, Tangshan City, Hebei Province, China, 063000 \\ a email: \\ b email: \\ ${ }^{\mathrm{C}}$ email: \\ d email:
}

Keywords: Clinical Medicine, Students, Teaching Quality, Assurance System

\begin{abstract}
With the improvement of China's comprehensive national strength, the process of internationalization of higher education has been accelerating and the scale has been expanding. The key to the success or failure of the clinical medical students education lies in the quality of education, so it is very important to establish and improve the teaching quality assurance monitoring system. Based on the author's teaching practice, this paper puts forward the assurance system of the teaching quality of undergraduate students in clinical medicine, namely: Improving the teaching management system, management mechanism and rules and regulations of foreign students; Strengthening the selection of teaching staff and the construction of the team; Carrying out teaching reform and teaching and research activities; Establishing the teaching quality feedback mechanism of international students; Optimizing the textbooks and other teaching materials.
\end{abstract}

\section{Introduction}

In the teaching practice of medical students, through continuous exploration, medical education management and educators have condensed out a clear international student education ideas, namely: According to the training objectives of foreign students, developing appropriate training programs and curriculum teaching plan; Establishing and improving the monitoring system of teaching quality assurance, strengthen the teaching process management and student management; Strengthening the logistics service to promote the steady development of the education of overseas students. We also fully realize that the key to the consolidation and sustainable development of medical students education is the quality of talent training. The focus of the education of the students has been transferred from the management of students to improve the quality of teaching, and constantly explore the establishment of medical students teaching quality assurance monitoring system. 


\section{Establishing a Teaching Management System for Students, Improving the Rules, Regulations}

and the Management Mechanism

Teaching management system and system construction is one of the important guarantees for the teaching quality of international students. Combined with the actual situation of the school, to establish a comprehensive management model: Medical College is responsible for teaching management, teaching quality and course construction; Personnel department is responsible for strengthening the training of teachers; Medical College is responsible for the late teaching and clinical practice; International Cooperation and Communication Institute is responsible for the hiring, management and use of foreign teachers. In the teaching management team, in charge of student training program, teaching plan, teaching syllabus, teaching activities, teaching materials, teacher training and so on. Timely expanding the functions of the international cooperation in foreign exchange, adding personnel to the composition of the administrative management of the education management team, responsible for enrollment and student enrollment and other relevant administrative management. Organizing the preparation of all the English teaching syllabus and syllabus for all courses. Improving the management information of students, so that the teaching of foreign students can be gradually institutionalized and standardized.

\section{Strengthening the Construction of Teaching Staff, Standardizing the Selection and Certification of Teaching Staff of Foreign Students}

For the improvement of teaching quality, the teaching staff is an important guarantee. Due to the use of English teaching, the students can not share the school and undergraduate students as excellent teachers. To this end, the school needs to increase the intensity of investment in teaching staff, to take a series of measures to solve the problem of education of foreign students. First of all, selecting the high level English teachers as the backbone of the teaching of foreign students, playing a major role. In the late clinical teaching, establishing curriculum and full-time teaching secretary to break the boundaries of the clinical faculty, integrating excellent teachers to bear the teaching work. Secondly, combined with the school's international strategy, taking into account the education of students in the short term, selecting the English teachers to study abroad to improve the teaching their abilities. Third, the school personnel department holds many kinds of English teacher training class in the school, such as the medical English teacher training class, spoken English intensive class, clinical medicine teacher training class and so on. Fourth, in the early days of the education of foreign students, a small amount of foreign teachers should be hired in the short term to make up for the shortage of their own teachers. The department of foreign teachers carries out the unified management for the foreign teachers, and asks them to participate in all the teaching activities in the teaching and research section.

\section{Actively Carrying out Education and Teaching Research to Promote the Improvement of Teaching Quality}

Foreign student education is a new teaching task, and it faces many new problems, to this end, we have strengthened the teaching and research. In view of the teaching tasks of students, we actively carry out teaching and research activities. First of all, taking the curriculum or the subject as the unit, actively to carry out collective lesson preparation, teaching etc., through the collective wisdom and efforts to help teachers improve the teaching abilities. Secondly, through the teaching garden, knowledge window and other forms, actively carrying out the communication and 
interactive activities between teachers and students. Third, actively carrying out teaching evaluation, according to the students' feedback information, comprehensively evaluating the teaching effect, reforming the teaching methods, examination methods, etc., to promote the teaching of foreign students.

According to the characteristics of foreign students, we continue to reform the teaching methods in order to obtain a better teaching effect. Theory course combined with multimedia and slide are conducted. Test class teaching takes the group as a unit, uses the heuristic, first explains the principle, grasps the essentials after the operation. In order to understand the situation of the students in a timely, we have increased the intensity of the examination and assessment, the reform of examination methods, etc..

\section{Improving the Teaching Quality Monitoring System for Foreign Students, and Ensure the Quality of Teaching}

Foreign student teaching is very different from ordinary undergraduate teaching in the teaching way and content, and it is almost a kind of brand-new teaching activity. In the teaching quality monitoring, we absorbed the Chinese common undergraduate teaching management experience, and combined with the actual situation of the teaching of foreign students, it has formed a set of multi direction internal quality feedback control system, which can make each link of teaching run under the supervision from beginning to end. The system can make teaching quality and teaching management improve, guarantee the teaching quality of international students.

To improve the quality of teaching, teaching and management staff at various levels lectures system should be adhered. From the start of the overseas students teaching, we established the system of the lectures system at various teaching and management staff in order to enhance the mutual communications, learning and promotion at the different teaching aspects. Also, the teaching ability and teaching quality of each overseas teacher should be reviewed comprehensively, which can be used in the selection and training of the teachers. By lectures attending, the teachers can correct the shortcomings and conduct the mutual communication and learning at the teaching content, teaching methods and education students in the classroom to improve the overall teaching ability of overseas teachers and promote the improvement of teaching quality.

Education Steering Committee should play an important role in guiding and supervising the overseas student teaching. Faced with the new tasks and difficulties, we rely on the collective wisdom to overcome them from beginning to the end to ensure the steady progress in the teaching of overseas students. College Education Steering Committee has played an important role in the whole process of teaching, including: The formulating the education plan and the teaching schedule; The discussion of the teaching problems regularly and irregularly at the special meetings and the bring up of the solutions and recommendations; The selections of the undertaking-task teachers by trail lectures of young and new teachers; The examination of three terms of teaching, including other teachings and the supervision and guidance of the overseas students teaching; Regular lectures, comprehensive evaluation of the effectiveness and quality of teachings, and provide advice and guidances for teaching administrations regulation teaching activities.

Setting up a foreign student assessment system and smooth feedback channels. The student is the subject of study, and the center of the teaching activity is the student. The teaching effect, teaching quality, evaluation of teaching management coming from the students are the most direct, which can reflect the true teaching situation. To this end, it needs to carry out online assessment of students. Holding a regular meeting of representatives of the students to listen to students' opinions and suggestions, such as teachers' teaching ability, language ability, teaching content arrangement, 
teaching materials and teaching materials selection, classroom teaching effect, experiment and practice content and arrangement, etc.. Insisting on the combination of regular teaching inspection and regular teaching, monitoring the progress of teaching and teaching content at any time, including papers, classroom teaching content, experimental teaching content, etc.. Regularly organizing students rated teaching activities, synthetically evaluating the teachers teaching, including teaching attitude, teaching method, teaching content, teaching effect, teaching order and so on. The important evaluation results are fed back to the teaching and research section, to promote teachers' input, reform and exploration, and to improve their teaching level. The Institute should regularly hold a special meeting, according to the feedback information of students, to take measures to control the teaching activities and improve the quality of teaching students.

According to the actual situation of students in teaching, it needs to adopt different assessment methods and undergraduate education, for example, in addition to the final examination of each course, increasing in the examination, the 3-5 times in the usual occasional break between the examination, timely to collect a large number of feedback information from students. The main objective to increase the assessment density is to urge the students to concentrate on their study. Special attention to their normal learning state can more accurately evaluate the students to grasp the knowledge of the situation, and effectively promote the improvement of teaching quality.

\section{Strengthening the Construction of Teaching Materials and Teaching Materials}

The teaching material is an important part of the teaching activity, and it is also one of the means to guarantee the teaching quality, so what materials are used for the study of the students have a great impact. In a few years of teaching, taking into account the differences university students receive education system, as well as different classes and other factors, the course is generally designated two textbooks. One for the students of medical materials, and the second is China's English version of medical materials, so two kinds of teaching materials can make up for each other, which can produce better teaching effect. In addition to the teaching materials, it also need to organize the preparation of a variety of lectures, auxiliary materials, experimental guidance, and it should be constantly revised and improved according to the actual effect of teaching, to make students teaching more standardized, improving the teaching level to ensure the quality of teaching.

\section{References}

[1] Zuo Chuan, Zeng Jing. Discussion on teaching practice of clinical medical courses for overseas students [J]. West China medicine, 2010,07:1344-1346.

[2] Wang Xingyue, Yi Jiang, Shu Mingrong. Investigation and analysis of medical students' Chinese curriculum evaluation [J]. modern preventive medicine, 2011,09:1647-1649.

[3] Chen Caoyi, Zhao Xiangqiang, Xie Xiaoling, Tan Xiangling. A preliminary study on the teaching of medical genetics for foreign students [J]. genetic, 2008,12:1647-1650.

[4] Xin Ying, Dong Lihua. Reflections on the practice of Pathology Teaching in foreign students [J]. Chinese Journal of laboratory diagnosis, 2014,08:1391-1393.

[5] Wang Jingmin, Shi Hong. The reform of teaching mode of gynecology and obstetrics for international students [J]. China Journal of modern medicine, 2012,16:110-111. 